\title{
Grain Boundary Sliding in a Superplastic Zinc-Aluminum Alloy Processed Using Severe Plastic Deformation
}

\author{
Megumi Kawasaki ${ }^{1}$ and Terence G. Langdon ${ }^{1,2, *}$ \\ ${ }^{1}$ Departments of Aerospace \& Mechanical Engineering and Materials Science University of Southern California, \\ Los Angeles, CA 90089-1453, U.S.A. \\ ${ }^{2}$ Materials Research Group, School of Engineering Sciences University of Southampton, Southampton SO17 1BJ, U.K.
}

A Zn-22\% Al eutectoid alloy was processed by Equal-Channel Angular Processing (ECAP) to produce a grain size of $\sim 0.8 \mu \mathrm{m}$. Tensile testing at $473 \mathrm{~K}$ gave a maximum elongation of $\sim 2230 \%$ at a strain rate of $1.0 \times 10^{-2} \mathrm{~s}^{-1}$. The significance of grain boundary sliding was evaluated by taking measurements of offsets in surface marker lines at an elongation of $30 \%$. The highest sliding contribution was recorded under testing conditions corresponding to the maximum superplastic elongation. Detailed measurements showed that relatively large offsets occurred at the $\mathrm{Zn}-\mathrm{Zn}$ and $\mathrm{Zn}-\mathrm{Al}$ interfaces but there were smaller offsets at the $\mathrm{Al}-\mathrm{Al}$ interfaces. It is concluded that grain boundary sliding is the dominant flow process during superplastic deformation. [doi:10.2320/matertrans.ME200720]

(Received July 31, 2007; Accepted September 3, 2007; Published October 11, 2007)

Keywords: equal-channel angular pressing, grain boundary sliding, superplasticity, ultrafine grains, zinc-aluminum alloy

\section{Introduction}

It is well established that superplastic flow may be achieved in metals when the grain size is very small, typically $<10 \mu \mathrm{m}$, and tensile testing is conducted at high temperatures where diffusion is reasonably rapid. ${ }^{1)}$ In practice, the required temperature is usually of the order of $\sim 0.5 T_{m}$ or higher, where $T_{m}$ is the absolute melting temperature of the material. Since these two conditions tend to be incompatible because the grains grow at elevated temperatures, the optimal materials for superplasticity are two-phase eutectic or eutectoid alloys or alloys where grain growth is restricted because of the presence of a fine dispersion of a second phase.

When a superplastic material is deformed in tension, the strain rate sensitivity, $m$, is given by:

$$
\sigma=K \dot{\varepsilon}^{m}
$$

where $\sigma$ is the steady-state flow stress, $\dot{\varepsilon}$ is the strain rate, $m$ is the strain rate sensitivity and $K$ is a constant incorporating the dependence on temperature and grain size. The strain rate sensitivity is equivalent to the slope of a logarithmic plot of $\sigma$ against $\dot{\varepsilon}$ and it is equal to the reciprocal of the stress exponent, $n$, used in conventional creep testing. Most superplastic metals exhibit a sigmoidal relationship between $\sigma$ and $\dot{\varepsilon}$, with a value for the strain rate sensitivity of $m \approx 0.5$ at intermediate strain rates. ${ }^{2)}$ The region where $m$ is high is generally termed Region II and at slower and faster strain rates the strain rate sensitivity is reduced to $\sim 0.1-0.3$ in the ranges denoted Regions I and III, respectively.

Recent developments have demonstrated there is an opportunity to produce materials with exceptionally small grain sizes through the application of severe plastic deformation (SPD) using various processing techniques in which high strains are imposed but without any significant change in the overall dimensions of the sample.,4) Equal-Channel Angular Pressing (ECAP) is one of the established SPD

*Corresponding author, E-mail: langdon@usc.edu processes for producing bulk metallic materials having ultrafine grain size that are generally in the submicrometer or possibly even the nanometer level. ${ }^{5)}$ Since ECAP can produce a high degree of homogeneity in the microstructure, ${ }^{6)}$ with exceptionally refined grains having an equiaxed configuration, there is an excellent potential for achieving good superplastic ductilities in these materials. A very recent tabulation documented a wide range of alloys where superplastic elongations have been recorded after processing by ECAP. ${ }^{7)}$

Grain boundary sliding is considered as the primary flow mechanism for achieving superplasticity in high temperature deformation. ${ }^{8)}$ Furthermore, since the theoretical model for superplasticity leads to a strain rate which varies inversely with grain size raised to a power of two, ${ }^{9}$ it follows that the very high elongations achieved after ECAP should occur within the region of high strain rate superplasticity ${ }^{10)}$ where the testing strain rate is at or above $10^{-2} \mathrm{~s}^{-1}$. This effect was first demonstrated several years ago in experiments on two aluminum-based alloys processed by ECAP. ${ }^{11)}$

The contribution of grain boundary sliding to the total strain has been measured in several conventional superplastic alloys where the grains sizes are typically in the range of $\sim 3-$ $5 \mu \mathrm{m} .{ }^{12-15)}$ By contrast, only limited information is at present available on the precise role of grain boundary sliding in ultrafine-grained materials processed by ECAP. Thus, the sliding contributions were measured after ECAP processing in an Al-1421 (Al-Mg-Li-Zr-Sc) alloy ${ }^{16)}$ and in the $\mathrm{Zn}-22 \%$ $\mathrm{Al}$ eutectoid alloy ${ }^{17)}$ with both materials tested over a limited range of strain rates from $1.0 \times 10^{-2}$ to $1.0 \times 10^{-1} \mathrm{~s}^{-1}$. Accordingly, the present investigation was initiated to provide more detailed information on the sliding contributions in a $\mathrm{Zn}-22 \% \mathrm{Al}$ alloy processed by ECAP with the experimental observations conducted over a wider range of strain rates.

\section{Experimental Materials and Procedures}

The experiments were performed using a commercial Zn- 
$22 \% \mathrm{Al}$ eutectoid alloy containing the following impurities in ppm: $\mathrm{Cr}<10, \mathrm{Cu} 20, \mathrm{Fe} \mathrm{70,} \mathrm{Mg}<10, \mathrm{Mn}<10$ and Si 70 . This alloy is composed of a binary microstructure of Al-rich and $\mathrm{Zn}$-rich phases and it was received as a plate with a thickness of $25 \mathrm{~mm}$. In the as-received condition, the average linear intercept grain size, $\bar{L}$, was measured as $\sim 1.8 \mu \mathrm{m}$. A rod with a diameter of $10 \mathrm{~mm}$ was machined from the plate and cut into several billets having individual lengths of $\sim 60 \mathrm{~mm}$. Prior to processing by ECAP, each billet was annealed in air at $473 \mathrm{~K}$ for 1 hour to remove any residual stresses.

Processing by ECAP was conducted following the principles described in earlier reports. ${ }^{5,18)}$ All samples were pressed using a solid die with two channels intersecting at an internal angle of $\Phi=90^{\circ}$ and with an additional outer angle of $\Psi=20^{\circ}$ representing the arc of curvature at the point of intersection. These values of $\Phi$ and $\Psi$ lead to an imposed strain of $\sim 1$ on each pass through the die. ${ }^{19)}$ The samples were processed by ECAP for a total of 8 passes at $473 \mathrm{~K}$ using processing route $B_{C}$ where the billet is turned by $90^{\circ}$ in the same direction between each pass. ${ }^{20)}$ Thus, the imposed strain for all samples was $\sim 8$. As demonstrated in an earlier report, the longitudinal grain size of this alloy is $\bar{L} \approx 0.8 \mu \mathrm{m}$ immediately after pressing for 8 passes at $473 \mathrm{~K}^{21 \text { ) }}$

Tensile specimens were cut parallel to the pressing direction after ECAP with gauge lengths of $4 \mathrm{~mm}$ and cross-sectional areas of $3 \times 2 \mathrm{~mm}^{2}$. These specimens were tested in tension using seven different initial strain rates from $1.0 \times 10^{-4}$ to $1.0 \mathrm{~s}^{-1}$ at $473 \mathrm{~K}$ with a testing machine operating at a constant rate of cross-head displacement. One set of specimens was pulled to failure to determine the nature of the relationship between $\sigma$ and $\dot{\varepsilon}$. The other set was pulled at three different strain rates to a predetermined elongation to permit a direct evaluation of the sliding contribution.

For the latter specimens used to investigate the significance of grain boundary sliding, one face of the gauge surface of each specimen was polished to a mirror-like finish prior to tensile testing and then a series of parallel marker lines was drawn on the polished surface parallel to the longitudinal axis. These marker lines were scribed by putting a small amount of $3 \mu \mathrm{m}$ diamond paste on a lens paper prepared by dipping in acetone and then placing the lens paper on the polished gauge surface and gently drawing it along the longitudinal axis. By this procedure, a series of well-defined markers were visible on the surface for subsequent measurements of the sliding offsets.

After cleaning with ethanol, these specimens were pulled to an elongation of $30 \%$ at strain rates of $1.0 \times 10^{-3}, 1.0 \times$ $10^{-2}$ or $1.0 \times 10^{-1} \mathrm{~s}^{-1}$ at a temperature of $473 \mathrm{~K}$, where the elevated temperature was achieved using a silicone oil bath to prevent oxidation of the polished surface during testing.

Following tensile testing, the samples were cleaned using acetone and the sliding offsets perpendicular to the tensile axis, $w$, were measured using a series of $~ 25-30$ photomicrographs taken for each specimen in a scanning electron microscope (SEM). All of the sliding offsets were recorded using three separate categories depending upon whether the pair of adjacent grains was $\mathrm{Zn}-\mathrm{Zn}, \mathrm{Al}-\mathrm{Al}$ or $\mathrm{Zn}-\mathrm{Al}$. In addition, the mean linear intercept grain size of each sample was measured in the longitudinal direction. In practice, more

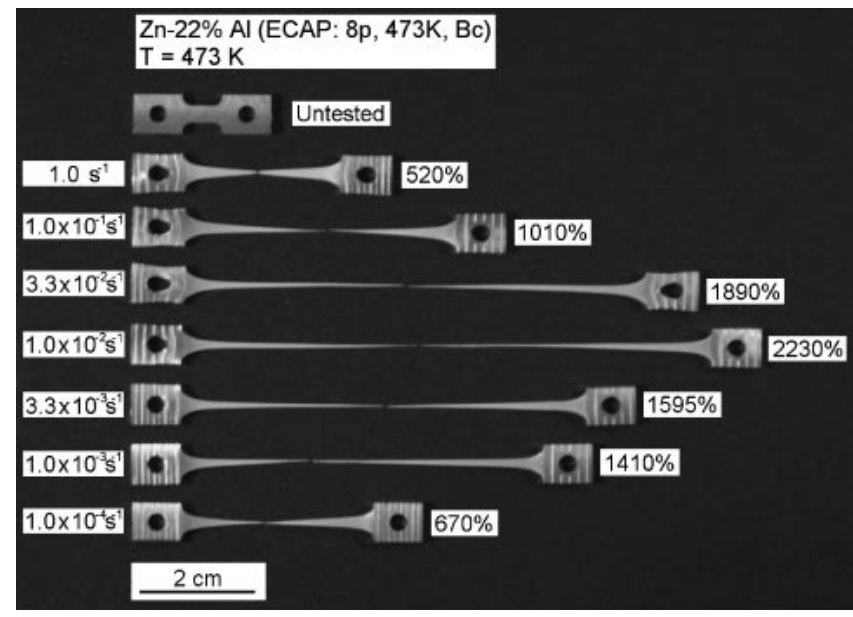

Fig. 1 The appearance of the specimens processed by ECAP for 8 passes at $473 \mathrm{~K}$ and pulled to failure at seven different strain rates at $473 \mathrm{~K}$ : the upper specimen is untested.

than 350 grain boundaries were used for each set of measurements of the sliding offsets and $>500$ grains were measured to determine the grain size. Special care was taken with each specimen to record all measurements reasonably close to the center of the gauge length, thereby avoiding any edge effects and any erroneous effects due to the proximity of the grip sections at either end.

\section{Experimental Results}

\subsection{Mechanical testing after ECAP}

Prior to the tensile testing and immediately following ECAP for 8 passes at $473 \mathrm{~K}$, a sample was heated to a temperature of $473 \mathrm{~K}$ and then cooled in air. The mean linear intercept grain size of this specimen was recorded as $\bar{L} \approx 0.9 \mu \mathrm{m}$ and this represents the longitudinal grain size of the material immediately before the tensile testing: ${ }^{21)}$ this grain size is slightly larger than the grain size of $\sim 0.8 \mu \mathrm{m}$ in the as-pressed condition.

For the samples tested to failure over a range of strain rates at $473 \mathrm{~K}$, Figure 1 shows the general appearance after failure. It is apparent that some specimens pulled out to exceptionally high elongations of $>1500 \%$ and the maximum recorded elongation was $\sim 2230 \%$ when using an initial strain rate of $1.0 \times 10^{-2} \mathrm{~s}^{-1}$ which is within the regime of high strain rate superplasticity. It is also apparent that all of the samples pulled to elongations of more than $1500 \%$ exhibit very uniform deformation within the gauge sections with no evidence for any significant necking. An absence of necking is an essentially characteristic of true superplastic flow. ${ }^{22)}$

Using the data obtained from the specimens pulled to failure, Figure 2 shows the variation of the elongation to failure (upper) and the flow stress (lower) with the initial strain rate. As in conventional superplastic materials, the results clearly divide into three distinct regimes with the superplastic Region II centered on an imposed strain rate of $\sim 10^{-2} \mathrm{~s}^{-1}$. From the lower curve, the strain rate sensitivity was measured as $m \approx 0.43$ in region II at strain rates of $\sim 1.0 \times 10^{-3}-1.0 \times 10^{-1} \mathrm{~s}^{-1}$ whereas the value of $m$ was reduced to $\sim 0.24$ at strain rates lower than $\sim 1.0 \times 10^{-3} \mathrm{~s}^{-1}$. 


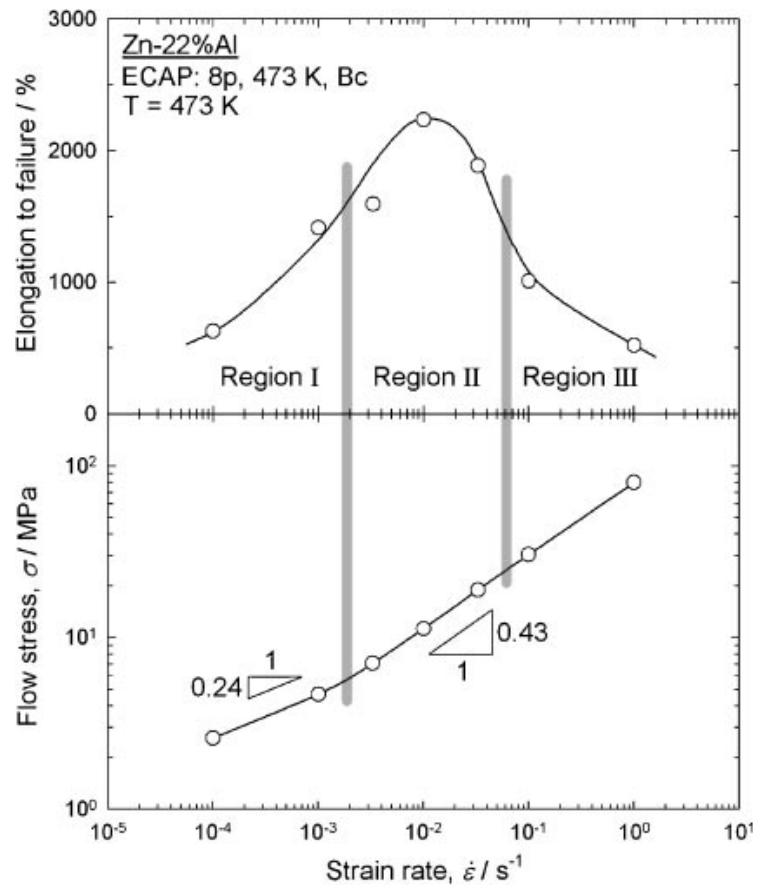

Fig. 2 The variation of elongation to failure (upper) and flow stress (lower) versus strain rate for a $\mathrm{Zn}-22 \% \mathrm{Al}$ alloy processed by ECAP and tested at $473 \mathrm{~K}$.

\subsection{Observations of grain boundary sliding}

\subsubsection{Appearance of the grain boundary offsets}

The microstructures on the polished surfaces within the gauge lengths were observed by SEM and the offsets of the marker lines were measured directly from the SEM images for each sample pulled to an elongation of $30 \%$. Figure 3 shows typical surface features for the samples tested at strain rates of (a) $1.0 \times 10^{-3}$, (b) $1.0 \times 10^{-2}$ and (c) $1.0 \times 10^{-1} \mathrm{~s}^{-1}$ where the tensile axis is vertical in each photo-micrograph. It should be noted that the grains appearing white are the $\mathrm{Zn}$ grains and the dark grains are $\mathrm{Al}$, thereby permitting a simple procedure for recording the nature of the interface at each separate sliding measurement. The marker lines are readily visible in each photo-micrograph and close inspection reveals sharp offsets perpendicular to the tensile axis at many of the grain boundaries. These offsets delineate the individual values of $w$.

Despite the evidence for sliding at all strain rates, closer inspection shows the sliding offsets tend to be relatively low in Region I at the slowest strain rate and these offsets are associated with smooth and curved lines. By contrast, the sample pulled at the fastest strain rates in Region III shows evidence for the development of cavities at the grain interfaces, with these cavities lying on boundaries oriented predominantly perpendicular to the tensile direction: for convenience, individual cavities are indicated by white arrows in Fig. 3(c). For testing in Region III, the marker lines are sharply-defined due to the short-term nature of the tests but the sliding offsets tend to be relatively small. A similar feature was reported earlier in a conventional $\mathrm{Zn}-22 \%$ $\mathrm{Al}$ alloy tested in tension without ECAP at a strain rate of $\left.1.0 \times 10^{-1} \mathrm{~s}^{-1} .23\right)$

The behavior in the superplastic Region II is different, as shown in Fig. 3(b). First, no voids are visible from surface
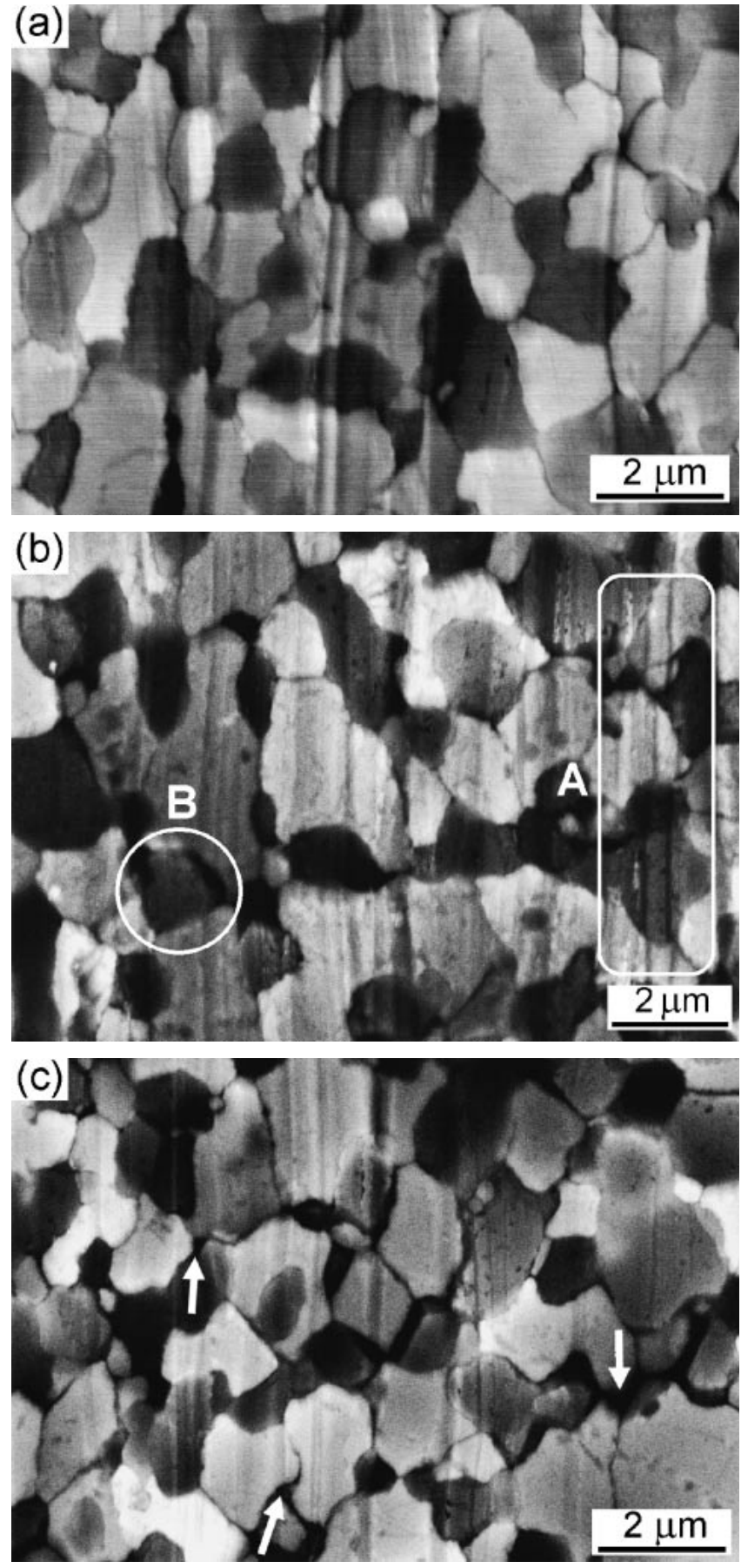

Fig. 3 Typical microstructures recorded at an elongation of $30 \%$ after testing in tension at $473 \mathrm{~K}$ at initial strain rates of (a) $1.0 \times 10^{-3}$, (b) $1.0 \times 10^{-2}$ and (c) $1.0 \times 10^{-1} \mathrm{~s}^{-1}$ : the tensile axis is vertical, the marker lines were used to take measurements of grain boundary sliding and areas A and B in (b) show examples of sharp marker offsets and extensive grain rotation, respectively.

observations so that the behavior differs from Region III. Second, the marker lines are sharply defined and display large sliding offsets. Examples of these sharp offsets are clearly visible in the rectangular section designated area A. In addition, there is very clear evidence for grain rotation in the circular area marked B.

\subsubsection{Estimating the contributions from grain boundary sliding}

The sliding contributions were determined from measure- 
Table 1 Offset measurements and sliding contributions determined for the $\mathrm{Zn}-22 \% \mathrm{Al}$ alloy after processing by ECAP: separate values are recorded both for the three sets of interfaces (on the left) and the total sample (on the right).

\begin{tabular}{cccccccc}
\hline$\dot{\varepsilon}\left(\mathrm{s}^{-1}\right)$ & $\begin{array}{c}\text { Type of } \\
\text { interface }\end{array}$ & $\begin{array}{c}\bar{w}_{i} \\
(\mu \mathrm{m})\end{array}$ & $\begin{array}{c}\bar{L}_{i} \\
(\mu \mathrm{m})\end{array}$ & $\begin{array}{c}\xi_{i} \\
(\%)\end{array}$ & $\begin{array}{c}\bar{w} \\
(\mu \mathrm{m})\end{array}$ & $\begin{array}{c}\bar{L} \\
(\mu \mathrm{m})\end{array}$ & $\begin{array}{c}\xi \\
(\%)\end{array}$ \\
\hline \multirow{3}{*}{$1.0 \times 10^{-1}$} & $\mathrm{Zn}-\mathrm{Zn}$ & 0.053 & 1.034 & 26 & & & \\
& $\mathrm{Al}-\mathrm{Al}$ & 0.037 & 0.985 & 19 & 0.047 & 1.012 & 23 \\
& $\mathrm{Zn}-\mathrm{Al}$ & 0.046 & - & 23 & & & \\
\hline \multirow{3}{*}{$1.0 \times 10^{-2}$} & $\mathrm{Zn}-\mathrm{Zn}$ & 0.084 & 1.024 & 41 & & & \\
& $\mathrm{Al}-\mathrm{Al}$ & 0.059 & 1.109 & 27 & 0.085 & 1.062 & 40 \\
& $\mathrm{Zn}-\mathrm{Al}$ & 0.090 & - & 42 & & & \\
\hline \multirow{3}{*}{$1.0 \times 10^{-3}$} & $\mathrm{Zn}-\mathrm{Zn}$ & 0.059 & 1.044 & 28 & & & \\
& $\mathrm{Al}-\mathrm{Al}$ & 0.044 & 1.090 & 20 & 0.062 & 1.064 & 29 \\
& $\mathrm{Zn}-\mathrm{Al}$ & 0.065 & - & 31 & & & \\
\hline
\end{tabular}

ments of the sliding offsets combined with measurements of the mean linear intercept grain sizes for the two separate phases. All grain size measurements were taken along the longitudinal axes and they are denoted as $\bar{L}$ for the average grain size when measuring all grains, $\bar{L}_{\mathrm{Zn}}$ for the individual $\mathrm{Zn}$ grains and $\bar{L}_{\mathrm{Al}}$ for the individual $\mathrm{Al}$ grains, respectively.

The strain due to grain boundary sliding, $\varepsilon_{\mathrm{gbs}}$, is related to the mean sliding offset, $\bar{w}$, through the expression ${ }^{24)}$

$$
\varepsilon_{\mathrm{gbs}}=\phi \frac{\bar{w}}{\bar{L}}
$$

where $\phi$ is a geometric constant estimated as equal to $\sim 1.5$. If $\varepsilon_{\text {total }}$ denotes the total strain in the specimen, the contribution of grain boundary sliding to the strain, $\xi$, may be expressed as a fractional relationship so that ${ }^{25)}$

$$
\xi=\frac{\varepsilon_{\mathrm{gbs}}}{\varepsilon_{\text {total }}}
$$

In practice, the individual contributions of sliding at each type of interface, $\xi_{i}$, may be estimated by using the appropriate values for the average sliding offset, $\bar{w}_{i}$, at that type of interface and the mean linear intercept grain size, $\bar{L}_{i}$, for that type of grain. Using this approach, individual values may be estimated for $\xi_{\mathrm{Zn}-\mathrm{Zn}}$ and $\xi_{\mathrm{Al}-\mathrm{Al}}$ based on the recorded values for $\bar{w}_{\mathrm{Zn}-\mathrm{Zn}}$ and $\bar{L}_{\mathrm{Zn}}$ for $\mathrm{Zn}-\mathrm{Zn}$ interfaces and $\bar{w}_{\mathrm{Al}-\mathrm{Al}}$ and $\bar{L}_{\mathrm{Al}}$ for Al-Al interfaces, respectively. The value of $\xi_{\mathrm{Zn}-\mathrm{Al}}$ was estimated from measurements giving $\bar{w}_{\mathrm{Zn}-\mathrm{Al}}$ and the value recorded separately for the mean linear intercept grain size, $\bar{L}$, when all grains are included.

Table 1 shows a summary of both the overall contribution from grain boundary sliding and the values of the sliding contributions associated with specific interfaces: the strain rate is given in the first column, the next four columns delineate the values of the sliding parameters associated with the different interfaces and the final three columns denote the sliding behavior when measurements are taken independent of the type of interface. It is readily apparent that a higher value of the sliding contribution was measured at a testing strain rate of $1.0 \times 10^{-2} \mathrm{~s}^{-1}$ where this corresponds to Region II and the maximum superplastic ductility. At this strain rate, the sliding contribution is given by $\xi \approx 40 \%$. However, the values of $\xi$ decrease when the samples are pulled at both a lower strain rate in Region I and a faster strain rate in Region III. This result is consistent with the nature of superplasticity in conventional materials where grain boundary sliding is dominant with large sliding offsets in Region II. It is reasonable to conclude from these measurements that sliding is a major flow process during superplastic deformation in Region II in the $\mathrm{Zn}-22 \% \mathrm{Al}$ alloy processed by ECAP.

Closer inspection of Table 1 shows that larger values of the sliding contributions occur at the $\mathrm{Zn}-\mathrm{Al}$ and $\mathrm{Zn}-\mathrm{Zn}$ interfaces whereas the sliding offsets are a minimum at the $\mathrm{Al}-\mathrm{Al}$ interfaces at all strain rates. This is consistent with several studies of superplasticity in the $\mathrm{Zn}-22 \% \mathrm{Al}$ eutectoid alloy both without $\mathrm{ECAP}^{14,15,23,26)}$ and after processing by ECAP. ${ }^{17)}$ It was also observed in detailed observations that the mean linear intercept grain sizes of the pressed samples increased slightly to $\bar{L} \approx 1.0 \mu \mathrm{m}$ after deformation to $30 \%$ at all strain rates.

It is possible to obtain a more detailed display of the sliding measurements by plotting the data in the form of histograms. Examples are shown in Fig. 4 where the number of boundaries, expressed as a percentage, is plotted against the individual measured values of $w$ for measurements taken in Regions I, II and III, respectively. Data are stacked from the three different boundary types in each vertical column in Fig. 4, thereby providing a direct measure both of the overall behavior for all boundaries and the behavior for each individual type of interface.

It is clear from inspection of these histograms that there was a large number of offsets having $w \approx 0.01 \mu \mathrm{m}$ in all specimens tested at the different strain rates. However, different features may be observed by individually examining the data associated with Regions I, II and III, respectively. Less than $40 \%$ of the boundaries have offsets of $\sim 0.01 \mu \mathrm{m}$ and over $60 \%$ of the boundaries have offsets in the range of $0.01 \sim 0.20 \mu \mathrm{m}$ in Region II, whereas almost $50 \%$ of the boundaries have offsets of $\sim 0.01 \mu \mathrm{m}$ when testing at strain rates in Regions I and III. Moreover, no boundaries have sliding offsets larger than $0.25 \mu \mathrm{m}$ in Region III whereas there are some clearly-defined offsets larger than $0.25 \mu \mathrm{m}$ in Regions I and II. It is noted from Table 1 that the average sliding contributions for both the $\mathrm{Zn}-\mathrm{Zn}$ and the $\mathrm{Zn}-\mathrm{Al}$ boundaries are equally high and it is now clear from Fig. 4 that both of these interfaces make high contributions in each value of the sliding offset at all strain rates.

\section{Discussion}

The results from these experiments, conducted after processing by ECAP, demonstrate a similarity with the behavior recorded in conventional superplastic materials. Thus, the data may be divided into the three conventional flow regions associated with superplastic alloys, with very high elongations occurring at intermediate strain rates in Region II.

To obtain a more comprehensive display of the precise role played by the different types of interfaces in the $\mathrm{Zn}-22 \% \mathrm{Al}$ eutectoid alloy, Table 1 was re-analyzed to give a pictorial representation of the relative sliding contributions, as a percentage, both for all of the boundaries and for the individual types of interfaces. The result is shown in Fig. 5 


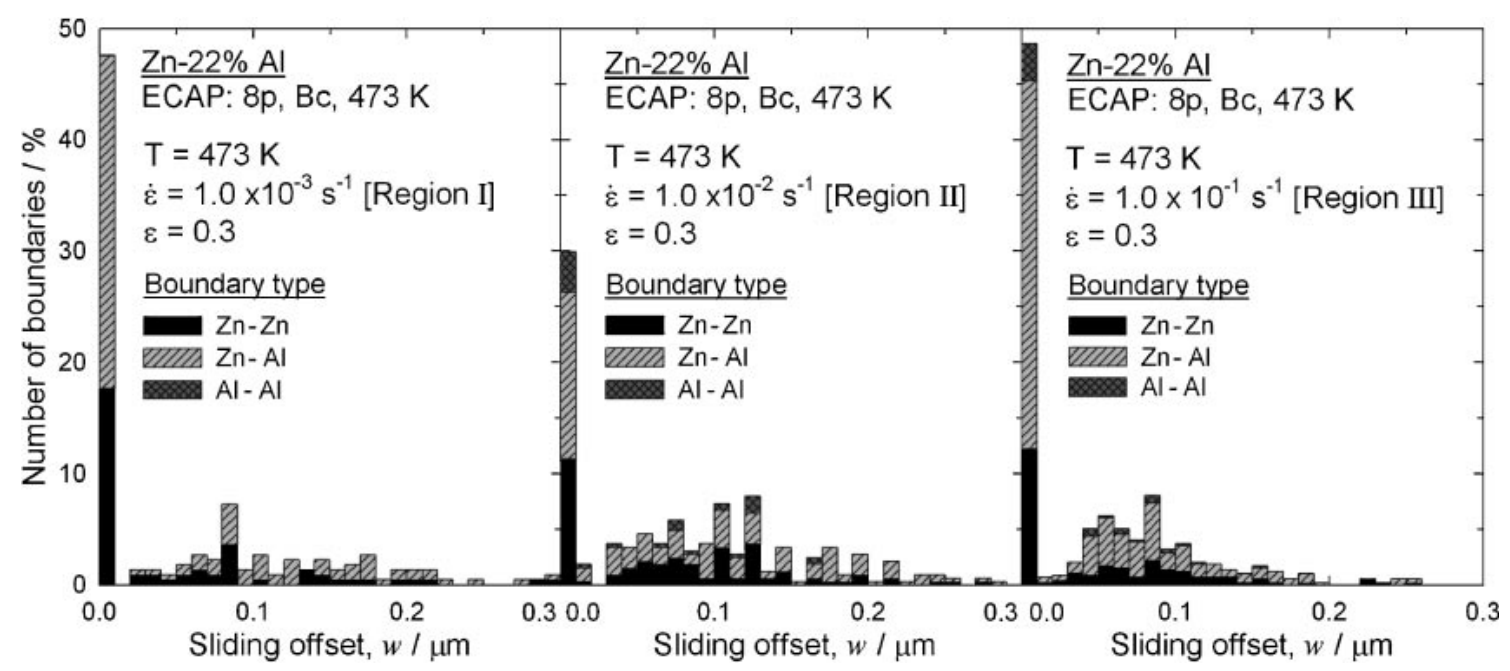

Fig. 4 The relative frequency of the number of boundaries expressed as a percentage versus values of the individual offsets after testing to an elongation of $30 \%$ at $473 \mathrm{~K}$ at strain rates of (a) $1.0 \times 10^{-3}$, (b) $1.0 \times 10^{-2}$ and (c) $1.0 \times 10^{-1} \mathrm{~s}^{-1}$ : the values are recorded separately for the $\mathrm{Zn}-\mathrm{Zn}, \mathrm{Zn}-\mathrm{Al}$ and $\mathrm{Al}-\mathrm{Al}$ interfaces.

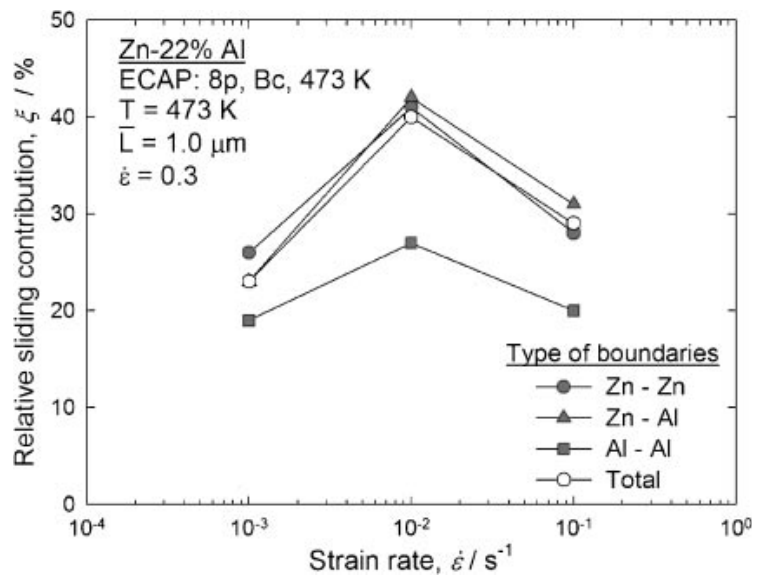

Fig. 5 The relative sliding contribution both of all boundaries and of the $\mathrm{Zn}-\mathrm{Zn}, \mathrm{Zn}-\mathrm{Al}$ and $\mathrm{Al}-\mathrm{Al}$ interfaces as a function of strain rate after testing to an elongation of $30 \%$ at $473 \mathrm{~K}$.

where the sliding contributions for all grain boundaries are represented using open points and the sliding contributions for the various interfaces are denoted using solid points. This plot demonstrates that all three types of interfaces behave similarly with the highest values of $\xi$ occurring consistently at a strain rate of $1.0 \times 10^{-2} \mathrm{~s}^{-1}$ in the superplastic Region II.

In practice, it is known that the occurrence of grain boundary sliding is related closely to the grain boundary character distribution during high temperature plastic flow. ${ }^{27)}$ This means in practice that higher sliding contributions are associated with high-angle grain boundaries and lower sliding contributions occur when there is a high fraction of low-angle boundaries. A very recent report documented the occurrence of sliding predominantly at high-angle grain boundaries in an Al-Mg-Sc-Zr alloy processed by ECAP. ${ }^{28)}$ Practically, it is well established that processing by ECAP leads to an increasing fraction of high-angle boundaries as the billet is pressed through larger numbers of passes. ${ }^{29-31)}$ In the present experiments, the billets of the $\mathrm{Zn}-\mathrm{Al}$ alloy were pressed through a total of 8 passes and it is reasonable to anticipate this large strain is sufficient to achieve a high fraction of high-angle boundaries. Furthermore, this conclusion is supported by the sliding measurements and the relatively large offsets recorded at many of the boundaries when testing in Region II.

Finally, it is necessary to address the value of the sliding contribution recorded in Region II where $\xi \approx 40 \%$. To understand this result, it is important to examine the nature of sliding in a polycrystalline matrix. First, it was noted earlier that measurements of sliding consistently underestimate the true sliding contributions because there is a physical limitation on the maximum boundary offsets that may be recorded from surface marker lines. ${ }^{8)}$ This means in effect that reported values of $\xi \approx 50-70 \%$ in conventional superplastic alloys underestimate the true sliding contributions and correspond to a situation where all of the strain is due to sliding. Second, the present apparent maximum sliding contribution of $\xi \approx 40 \%$ is a natural consequence of the limitations placed on sliding measurements when samples are pulled to high elongations. This effect was demonstrated earlier in two sets of experiments using a conventional $\mathrm{Zn}$ $22 \% \mathrm{Al}$ alloy without processing by ECAP where the linear intercept grain sizes were $\sim 3.8 \mu \mathrm{m}^{14)}$ and $\sim 3.0 \mu \mathrm{m}^{15)}$ and the samples were pulled to predetermined elongations of $\sim 100 \%$ and $\sim 35 \%$, respectively. In these experiments, the maximum sliding contributions in Region II were measured as $\sim 18 \%$ and $\sim 32 \%$, respectively. Thus, the present results are fully consistent with these earlier values when taking into consideration the smaller grain size and the predetermined elongation of $30 \%$ used in all of the tests. In addition, experiments on a dilute $\mathrm{Zn}-\mathrm{Al}$ alloy have shown that sliding starts on all of the grain boundaries from the earliest stages of tensile straining, ${ }^{32)}$ thereby confirming the validity of invoking a model based on a physical limitation in the maximum possible boundary offsets.

It is important to note also that, although sliding occurs more easily to produce boundary offsets perpendicular to the specimen surface, the physical differences between these 
vertical and horizontal offsets are incorporated into the procedures available for estimating the values of the sliding contribution $\xi$ in any selected material. ${ }^{24,25)}$ Therefore, the measured sliding contributions are not dependent upon whether offset measurements are recorded in the plane of the specimen surface or perpendicular to the surface.

Taking these various limitations into consideration, it is concluded that, as in conventional alloys, the present results show that grain boundary sliding accounts for essentially all of the strain in the superplastic Region II in the $\mathrm{Zn}-22 \% \mathrm{Al}$ alloy produced by processing using ECAP.

\section{Summary and Conclusions}

(1) $\mathrm{A} \mathrm{Zn-22 \%} \mathrm{Al}$ eutectoid alloy was processed by ECAP for 8 passes at $473 \mathrm{~K}$ to refine the grain size to $\sim 0.8 \mu \mathrm{m}$. Testing to failure in tension at $473 \mathrm{~K}$, a maximum elongation of $\sim 2230 \%$ was obtained at a strain rate of $1.0 \times 10^{-2} \mathrm{~s}^{-1}$. This result confirms the occurrence of high strain rate superplasticity.

(2) Measurements were taken of the grain boundary sliding offsets at predetermined elongations of $30 \%$ using three different initial strain rates. These measurements show that relatively large offsets occur at the $\mathrm{Zn}-\mathrm{Zn}$ and $\mathrm{Zn}$ $\mathrm{Al}$ interfaces whereas the offsets are smaller at the $\mathrm{Al}$ $\mathrm{Al}$ interfaces.

(3) The highest sliding contribution was recorded under experimental conditions corresponding to the largest superplastic elongation, thereby confirming that grain boundary sliding is an important flow process for achieving superplastic ductilities in the $\mathrm{Zn}-22 \% \mathrm{Al}$ alloy processed by ECAP.

(4) A largest sliding contribution of $\sim 40 \%$ was obtained in the superplastic Region II. This value is consistent with values reported for conventional superplastic alloys and, because of inherent physical limitations on the measuring process at higher elongations, it corresponds to a situation where essentially all of the strain is due to grain boundary sliding.

\section{Acknowledgments}

This work was supported by the U.S. Army Research Office under Grant No. W911NF-05-1-0046.

\section{REFERENCES}

1) T. G. Langdon: Metall. Trans. A 13A (1982) 689-701.

2) T. G. Langdon: Mater. Sci. Eng. A137 (1991) 1-11.

3) R. Z. Valiev, N. K. Krasilnikov and N. K. Tsenev: Mater. Sci. Eng. A137 (1991) 35-40.

4) R. Z. Valiev, R. K. Islamgaliev and I. V. Alexandrov: Prog. Mater. Sci. 45 (2000) 103-189.

5) R. Z. Valiev and T. G. Langdon: Prog. Mater. Sci. 51 (2006) 881-981.

6) C. $\mathrm{Xu}, \mathrm{M}$. Furukawa, Z. Horita and T. G. Langdon: Mater. Sci. Eng. A398 (2005) 66-76.

7) M. Kawasaki and T. G. Langdon: J. Mater. Sci. 42 (2007) 1782-1796.

8) T. G. Langdon: Mater. Sci. Eng. A174 (1994) 225-230.

9) T. G. Langdon: Acta Metall. Mater. 42 (1994) 2437-2443.

10) K. Higashi, M. Mabuchi and T. G. Langdon: ISIJ Intl. 36 (1996) 14231438.

11) R. Z. Valiev, D. A. Salimonenko, N. K. Tsenev, P. B. Berbon and T. G. Langdon: Scripta Mater. 37 (1997) 1945-1950.

12) R. B. Vastava and T. G. Langdon: Acta Metall. 27 (1979) 251-257.

13) T. G. Langdon: J. Mater. Sci. 16 (1981) 2613-2616.

14) P. Shariat, R. B. Vastava and T. G. Langdon: Acta Metall. 30 (1982) 285-296.

15) Z.-R. Lin, A. H. Chokshi and T. G. Langdon: J. Mater. Sci. 23 (1998) 2712-2722.

16) R. K. Islamgaliev, N. F. Yunusova, R. Z. Valiev, N. K. Tsenev, V. N. Perevezentsev and T. G. Langdon: Scripta Mater. 49 (2003) 467-472.

17) P. Kumar, C. Xu and T. G. Langdon: Mater. Sci. Eng. A410-411 (2005) 447-450.

18) M. Furukawa, Z. Horita, M. Nemoto and T. G. Langdon: J. Mater. Sci. 36 (2001) 2835-2843.

19) Y. Iwahashi, J. Wang, Z. Horita, M. Nemoto and T. G. Langdon: Scripta Mater. 35 (1996) 143-146.

20) M. Furukawa, Y. Iwahashi, Z. Horita, M. Nemoto and T. G. Langdon: Mater. Sci. Eng. A257 (1998) 328-332.

21) P. Kumar, C. Xu and T. G. Langdon: Mater. Sci. Eng. A429 (2006) 324-348.

22) T. G. Langdon: Metal Sci. 16 (1982) 175-183.

23) K. Duong and F. A. Mohamed: Acta Mater. 46 (1998) 4571-4586.

24) T. G. Langdon: Metall. Trans. 3 (1972) 797-801.

25) T. G. Langdon: J. Mater. Sci. 41 (2006) 597-609.

26) K. Duong and F. A. Mohamed: Metall. Mater. Trans. 32A (2001) 103113.

27) T. Watanabe: Mater. Sci. Eng. A166 (1993) 11-28

28) P. Málek, K. Turba, M. Cieslar, I. Drbohlav and T. Kruml: Mater. Sci. Eng. A462 (2007) 95-99.

29) S. D. Terhune, D. L. Swisher, K. Oh-ishi, Z. Horita, T. G. Langdon and T. R. McNelly: Metall. Mater. Trans. 33A (2002) 2173-2184.

30) P. L. Sun, C. Y. Yu, P. W. Kao and C. P. Chang: Scripta Mater. 47 (2002) 377-381.

31) A. P. Zhilyaev, D. L. Swisher, K. Oh-ishi, T. G. Langdon and T. R. McNelley: Mater Sci. Eng. A429 (2006) 137-148.

32) P. Málek: Mater. Sci. Eng. A268 (1999) 132-140. 